\title{
Parkinson's Disease and Segmental Coordination during Turning: I. Standing Turns
}

\author{
Sakineh Akram, James S. Frank, Mandar Jog
}

\begin{abstract}
Objective: Many of the falls among people with Parkinson's disease (PD) occur during sudden, on-the-spot turning which requires systematic reorientation of axial segments towards the new direction. We examined whether a disturbance in the coordination of segmental reorientation is an important cause of turning difficulty in individuals with PD and is altered by dopaminergic medication. Methods: The sequence and timing of segmental reorientation during $45^{\circ}$ and $90^{\circ}$ on-the-spot turns was examined in fourteen individuals with PD while "off" and "on" medication and nineteen healthy controls (HC). Results: Regardless of the magnitude of the turn, HC reoriented their head, shoulder, and pelvis simultaneously followed by mediolateral foot displacement. PD patients displayed temporal coordination patterns similar to the HC. PD however, reduced the velocity and early magnitude of reorientation of each body segment which were both slightly improved by dopaminergic medication. Conclusion: Our finding that the HC and PD patients turn en bloc when the turn is predictable and there are no time constraints shows that the strategy of en bloc turning is not wrong if the movement parameters are unconstrained. However, in real life situations, which usually require quick and unpredictable turns, the en bloc strategy may be unsafe and more likely to result in falls. While in such situations HC are able to change the strategy from en bloc to sequential segmental turning, PD patients may not be able to do so and continue to turn en bloc.
\end{abstract}

RÉSUMÉ: Maladie de Parkinson et coordination segmentaire au cours des changements de direction : I. les changements de direction sur place. Objectif : Plusieurs chutes chez les parkinsoniens surviennent pendant un changement de direction subit, sur place, qui requiert une réorientation systématique des segments axiaux vers une nouvelle direction. Nous avons examiné si une perturbation de la coordination de la réorientation segmentaire est une cause importante des difficultés éprouvées par les parkinsoniens quand ils changent de direction et si la médication dopaminergique les modifient. Méthode : La séquence et la chronologie de la réorientation segmentaire au cours de changements de direction sur place à $45^{\circ}$ et à $90^{\circ}$ ont été examinées chez 14 parkinsoniens sous médication en phase « off » et en phase « on » et chez 19 sujets témoins en bonne santé. Résultats : Quelle que soit l'ampleur du changement de direction, les sujets témoins réorientaient leur tête, leurs épaules et leur bassin simultanément et ceci était suivi d'un déplacement médio-latéral des pieds. Chez les parkinsoniens, la séquence temporelle de la coordination était semblable à celle des témoins. Cependant, au début du mouvement, la vitesse et l'ampleur de la réorientation de chaque segment corporel étaient diminuées chez les parkinsoniens. Ceci était amélioré légèrement par la médication dopaminergique. Conclusion : Notre observation que les sujets témoins et les parkinsoniens tournent en bloc quand le changement de direction est prévisible et qu'il n'existe pas de contrainte de temps démontre que la stratégie du changement de direction en bloc n'est pas en cause si les paramètres du mouvement ne sont pas exécutés sous contrainte. Cependant, dans une situation réelle, qui nécessite habituellement des changements de direction rapides et imprévisibles, la stratégie du changement de direction en bloc peut être dangereuse et plus susceptible de causer des chutes. Dans de telles situations, alors que les témoins sont capables de passer d'une stratégie en bloc à un stratégie segmentaire séquentielle, les parkinsoniens eux peuvent ne pas être capables de le faire et continuent à changer de direction en bloc.

Can J Neurol Sci. 2013; 40: 512-519

\section{INTRODUCTION}

Postural instability is one of the cardinal symptoms of Parkinson's disease $(\mathrm{PD})^{1}$, and is exaggerated in specific circumstances such as turning ${ }^{2,3}$. Difficulty turning is a sensitive predictor of the two key symptoms of PD locomotion: freezing and falling ${ }^{4}$. The high prevalence of turning in everyday life ${ }^{5}$ and the association of turning with falls and freezing in PD highlight the importance of understanding the turning impairment in this population.

Previous research has shown that while walking, PD patients turn slower, make wider turns with narrower steps and take more steps to complete the turn ${ }^{6-12}$. The temporal organization of segmental reorientation during walking turns also is impaired even in PD participants who demonstrate normal spatio- temporal gait parameters during straight walking and exhibit negligible or no axial rigidity ${ }^{6,7,13}$. In comparison with agematched healthy elderly, segmental reorientation is delayed significantly in PD. Furthermore, while healthy elderly turn their head, upper trunk and pelvis in a craniocaudal sequence,

From the Department of Kinesiology (SA, JSF), University of Waterloo; St. Jerome's University (JSF), Waterloo; Movement Disorders Program (MJ), London Health Sciences Centre, London, Ontario, Canada.

Received June 11, 2012. Final Revisions Submitted February 20, 2013. Correspondence to: Sakineh Akram, University of Waterloo, 200 University Avenue West, Waterloo, Ontario, N2L 3G1, Canada. Email: sbakram@uwaterloo.ca. 
individuals with PD turn their head and upper trunk together followed by the rotation of pelvis ${ }^{6,7,13}$.

On-the-spot turns are also exceptionally prevalent in daily activities and many falls in PD happen while making such turns. Preparing food at the kitchen counter, answering the phone and even rising from a chair and ambulating involve some degree of on-the-spot turns. During on-the-spot turns, PD patients turn slower and take more steps than healthy controls $(\mathrm{HC})^{4,14,15}$. Only a few studies have examined the temporal organization of segmental reorientation during on-the-spot turns in $\mathrm{PD}^{14-16}$ and results are inconsistent. Hong and colleagues ${ }^{14}$ report that during $180^{\circ}$ on-the-spot turns, healthy individuals demonstrate a craniocaudal sequence of turning. Individuals with PD "off" medication however start turning en bloc and the relative rotation between body segments was reduced in comparison with $\mathrm{HC}^{14}$. A later study by Hong and colleagues ${ }^{16}$ reported that medication did not alter turning behavior; in both "off" and "on" conditions, individuals with PD demonstrated a "nearly simultaneous onset" of segments rotation while making $180^{\circ}$ onthe-spot turns. Although dopaminergic medication caused a slight, non-significant increase in the absolute and relative amplitude of rotation of body segments, the amplitude of segments rotation remained well below the values reported for age-matched $\mathrm{HC}^{16}$.

Anastasopoulos and colleagues ${ }^{15}$ reported that predictability of target location influences the pattern of segmental reorientation during on-the-spot turns. They examined turns varying in magnitude from 45 to 180 degrees. A top-down reorientation of segments was observed for $\mathrm{HC}$ and $\mathrm{PD}$ participants "on" medication groups when turning toward an unpredictable target location; a more en bloc segmental reorientation was observed in both groups when turning toward a predictable target. Compared with HC, PD patients took multiple smaller steps to complete the turn and turned more slowly.

This study, and a companion paper, examined turning behavior in healthy older adults and individuals with moderate PD symptoms in "off" and "on" medication states when performing on-the-spot turns (this paper) and turns initiated while walking (companion paper). We examined small $\left(45^{\circ}\right)$ and large $\left(90^{\circ}\right)$ turns to determine if turn magnitude differentiated the turning behavior of $\mathrm{HC}$ versus individuals with PD. All turns were self-paced and toward predictable targets, so as to allow comparison of turning strategies during on-the-spot turns and turns while walking and to minimize any impact of cognitive differences between groups.

\section{MeTHODS}

\subsection{Participants}

Fourteen individuals with PD and nineteen age-matched HC participated in this study (Table $1^{17}$ ). Patients were diagnosed with idiopathic PD by their neurologist and were free from any musculoskeletal or additional neurologic conditions. Three patients reported one fall each during the six months prior to testing. Healthy controls were free from any neurological or musculoskeletal impairment and had no history of falls in the six months prior to the experiment.

Table 1: Characteristics of participants

Healthy participants: $(\mathrm{n}=19,10 \mathrm{M}, 9 \mathrm{~F})$, Mean age 66 years (SD 4.2)

\begin{tabular}{|c|c|c|c|c|c|c|c|}
\hline $\begin{array}{l}\text { PD participant's } \\
\text { ID }\end{array}$ & Gender & $\begin{array}{c}\text { Age } \\
\text { (year) }\end{array}$ & $\begin{array}{c}\text { PD Duration } \\
\text { (year) }\end{array}$ & Medication & $\begin{array}{c}\text { Daily Dose }^{\Delta} \\
\text { (mg) }\end{array}$ & $\begin{array}{l}\text { UPDRS } \dagger \text { Score } \\
\text { "Off" Med }\end{array}$ & $\begin{array}{c}\text { UPDRS } \dagger \text { Score } \\
\text { "On" Med }\end{array}$ \\
\hline 1 & $\mathrm{~F}$ & 64 & 5 & Pramipexole & 201 & 30.5 & 16 \\
\hline 2 & $\mathrm{~F}$ & 57 & 4 & Levodopa/Carbidopa, Trihexyphenidyl & 400 & 38 & 32.5 \\
\hline 3 & M & 70 & 9 & Levodopa/Carbidopa & 450 & 39 & 23.5 \\
\hline 4 & $\mathrm{~F}$ & 64 & 5 & Levodopa/Carbidopa & 500 & 22 & 12.5 \\
\hline 5 & M & 67 & 6 & Levodopa/Carbidopa & 800 & 36 & 24 \\
\hline 6 & M & 70 & 2 & Rasagiline & $1^{\Omega}$ & 20.5 & 12 \\
\hline 7 & $\mathrm{~F}$ & 68 & 7 & Ropinirole & 200.04 & 13.5 & 6.5 \\
\hline $\mathbf{8}^{\lambda}$ & M & 62 & 5 & Levodopa/Carbidopa \& Pramipexole & 401.5 & 14.5 & 6 \\
\hline $9^{\lambda}$ & $\mathrm{F}$ & 70 & 8 & Levodopa/Carbidopa & 450 & 12 & 12 \\
\hline 10 & M & 73 & 1 & Rasagiline & $1^{\Omega}$ & 18 & 9.5 \\
\hline $11^{\sigma}$ & M & 62 & 8 & Levodopa/Carbidopa & 1000 & 29 & 20.5 \\
\hline 12 & M & 63 & 3 & Levodopa/Carbidopa & 400 & 19.5 & 12 \\
\hline $13^{\lambda}$ & $\mathrm{F}$ & 70 & 5 & Levodopa/Carbidopa \& Ropinirole & 733.36 & 14 & 8 \\
\hline 14 & $\mathrm{~F}$ & 74 & 4 & Levodopa/Carbidopa & 600 & 25 & 22 \\
\hline Mean & & 67 & 5 & & & $24 *$ & 16 \\
\hline SD & & 4.8 & 2.3 & & & 9.4 & 7.8 \\
\hline
\end{tabular}

$\dagger$ Unified Parkinson's Disease Rating Scale (total motor sub-score); ${ }^{*}$ significantly different from "on" medication. ${ }^{\lambda}$ Participants who reported one fall each during the six months prior to testing. ${ }^{\varnothing}$ The only participant who demonstrated freezing. ${ }^{\Delta}$ Daily dose of the levodopa equivalent of dopaminergic medications ${ }^{17} \Omega(\mathrm{mg}$ of Rasagiline per day. Currently there is no formula for calculating the levodopa equivalent of Rasagiline. $\mathrm{SD}=$ standard deviation; $\mathrm{M}=$ Male; $\mathrm{F}=$ Female; $\mathrm{n}=$ Number 
Participants were informed about the experimental procedure before signing a consent form. All procedures were approved by the Office of Research Ethics at the University of Waterloo and the University of Western Ontario.

\subsection{Data Collection}

Twelve infra-red emitting diodes (IREDs) were mounted on the following locations of the body, bilaterally: ear, acromion process, anterior superior iliac spine, hip joint, lateral malleolus, and the big toe. One IRED was mounted on the chin and another on the participants' chest approximately $5 \mathrm{~cm}$ below the jugular notch. Four Optotrak 3D imaging system cameras (Northern Digital Inc., Canada) were used to record IRED data at $120 \mathrm{~Hz}$. Participants stood on the lab floor with their arms crossed in front of their chest. Four pylons were placed approximately $3 \mathrm{~m}$ away from them at $45^{\circ}$ and $90^{\circ}$ to their right and left. Before each trial participants were told about the direction and the magnitude of the turn for that trial, i.e., they were told which pylon they should turn toward. Participants were instructed to turn (following a verbal "go" signal) with their whole body (including their feet) and at their natural, comfortable speed to face the designated pylon. They were also instructed to avoid pivoting their feet and to turn by lifting and moving the entire foot. Participants turned while having their arms crossed in front of their chest. This approach served two purposes: 1) it prevented blocking of the IREDs positioned on the pelvis area; 2) since arm swinging is reduced in $\mathrm{PD}^{18}$, this strategy eliminated the possible contribution of arm swing on segmental reorientation for both groups.

Participants performed three trials in each of the four directions; however, due to the limited equipment and space, data were collected only during the right-turn trials (six trials). Participants were unaware that data were not being collected during the left-turn trials. The order of the right-turn and left-turn trials was randomized. Upon completion of all trials, each participant's spinal flexibility was measured using the Functional Axial Rotation (FAR) test ${ }^{19}$.

Individuals with PD were tested in "off" and "on" medication states. They were asked to skip the last dose of their dopaminergic medication prior to coming to the laboratory. Upon arrival, they were tested while "off" medication (12 hours). Then they were asked to take their dopaminergic medication. The second round of trials started when the participant reported that he/she was in "on" state (at least an hour after taking the medication $)^{20,21}$. Spinal flexibility of each individual with PD was measured in both "off" and "on" medication states using the FAR test. Rest periods were provided throughout the experiment upon the participants' request.

\subsection{Data processing}

The Optotrak data were low-pass filtered (Butterworth) prior to analyses with a cut-off frequency of $6 \mathrm{~Hz}$. The yaw angular displacement profiles of the head, shoulder (upper trunk), and pelvis in the global reference frame were determined from the three non-co-linear IREDs placed on each segment. The head segment was created using the IREDs placed on the ears and chin, the shoulder segment was created using the two IREDs placed on the participant's shoulders and the one on his/her chest, and the pelvis segment was created using the three IREDs placed on the right and left anterior superior iliac spine and the right hip joint. Angular displacement profiles were used to determine the start of the turn. For each trial, data collection started at least one second before the participant was instructed to turn. The initiation of the head, shoulder and pelvis turn was calculated as the point in time that the angular displacement data indicated the start of the turn towards the new direction, providing the deviation continued beyond the range of angular displacement of each segment during the initial one second quiet stance. Although the start times were clearly identifiable since the turns were made from quiet stance, we used velocity profiles to ensure that the start points marked were not outliers and that they accurately indicated the start of the movement. Toe displacement profiles were used to determine the onset of change in the orientation of the feet. For each foot, the start of turn was calculated as the point in time that the toe displacement data indicated the start of the turn towards the new direction, providing the deviation continued beyond the range of toe displacement during quiet stance.

Initiation of head reorientation was considered the reference time $(0 \mathrm{~ms})$. Delay time (DT) refers to the delay in reorientation in the yaw plane of shoulder (DT-Shoulder), pelvis (DT-Pelvis), and the foot that deviated first towards the new direction (DTFoot) relative to the start of head turn.

For each trial, the peak velocity of head, shoulder and pelvis in yaw direction was calculated. The magnitude of head, shoulder and pelvis turn was recorded from the time when the segment initiated reorientation to the onset of mediolateral foot displacement.

\subsection{Data Analysis}

\subsubsection{Effects of $P D$}

Due to lack of main effect for gender, this factor was removed in further analysis.

Data collected from the HC and PD participants "off" medication were compared to examine the effects of PD. A three-way repeated measure analyses of variance (ANOVA) with group (HC vs. PD) as between factor and segment (shoulder, pelvis, foot), and magnitude $\left(45^{\circ}, 90^{\circ}\right)$ as within factors was performed on DT-Shoulder, DT-Pelvis and DT-Foot. Since initiation of head rotation is considered as the reference time, head could not be included in the above analysis. Therefore, $t-$ tests were performed to determine if the means of DT-Shoulder, DT-Pelvis and DT-Foot were significantly different from zero (initiation of head reorientation). A Bonferroni correction was used to correct for multiple comparisons.

Between group comparisons of velocity and the degree of turn achieved by different segments at the onset of ML foot displacement were examined using a three-way repeated measure analysis of variance (ANOVAs) with group (HC vs. PD) as between factor and segment (head, shoulder, pelvis), and magnitude $\left(45^{\circ}, 90^{\circ}\right)$ as within factors.

\subsubsection{Effects of dopaminergic medications}

Data obtained from PD participants "off" and "on" medication were compared to examine possible effect of dopaminergic medications on segmental reorientation. To examine the effect of medication on the sequence and timing of 
segmental reorientation during small and large turns, a three-way repeated measure ANOVA with condition ("off" and "on"), segment (shoulder, pelvis, foot), and magnitude of the turn $\left(45^{\circ}\right.$, $90^{\circ}$ ) as within factors was performed on DT-Shoulder, DT-Pelvis and DT-Foot. T-tests were performed to determine if the means of the DTs in segment reorientation are significantly different from zero (initiation of head reorientation). A Bonferroni correction was used to correct for multiple comparisons.

To examine the effect of medication on the velocity and the amount of turn achieved by each segment at the onset of ML foot displacement, three-way repeated measure ANOVAs were performed with condition ("off" and "on"), segment (head, shoulder, pelvis), and magnitude of the turn $\left(45^{\circ}, 90^{\circ}\right)$ as within factors.

For conditions showing a main or interaction effect of a factor, Tukey's Studentized Range Test (HSD) was performed to determine which means were different from the others. A significance value $(\mathrm{P})$ of less than 0.05 was used to test statistical significance.

\section{RESULTS}

Sample profiles in Figure 1 display en bloc rotation for a $\mathrm{HC}$ and a PD participant "on" and "off" medication. Figure 1 shows the profiles of segmental reorientation of head, shoulder, and pelvis in the yaw plane during a $45^{\circ}$ and a $90^{\circ}$ turn, as well as head-on-shoulder and shoulder-on-pelvis angular displacements.
The graphs show simultaneous onset of head, shoulder and pelvis rotation for both the HC and PD participants "on" and "off" medication; this pattern was observed for $45^{\circ}$ and $90^{\circ}$ turns. The $90^{\circ}$ turn revealed faster rotation of the head (steeper slope) than the shoulders and pelvis for the HC participant. Conversely, for the individual with PD while "off" medication this separation did not occur and all three segments continued to turn in unison. The small head-on-shoulder rotation was restored when the individual with PD was "on" medication (Figure 1).

\subsection{Effects of PD}

The sequence and timing of segment reorientation was similar for HC and PD participants "off" medication. The ANOVA revealed no significant main or interaction effect of group on the sequence and timing of the segmental reorientation. Furthermore, results of the t-tests revealed that DT-Shoulder and DT-Pelvis were not significantly different from zero (i.e., the onset of head rotation) for both groups and magnitudes of turn. However, DT-Foot was significantly different from zero for both groups. These results indicate that regardless of the magnitude of the turn, both HC and PD participants turned their head, shoulder, and pelvis simultaneously. The simultaneous reorientation of the head and trunk was followed by foot reorientation (Figure 2).

However, the ANOVA revealed significant main effects of segment $(\mathrm{F}(2,62)=336.70, \mathrm{P}<0.0001)$ and magnitude of the turn
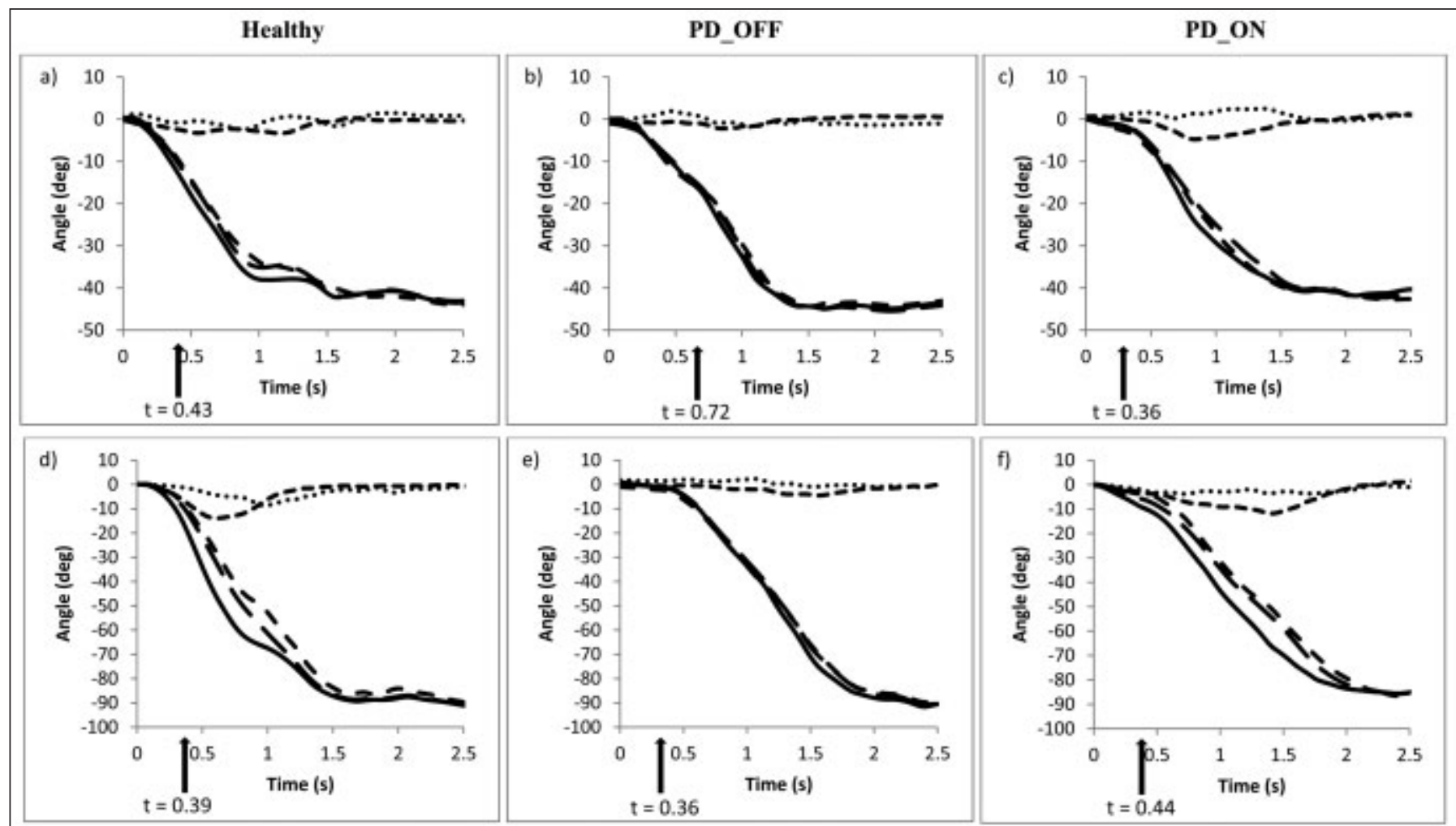

Figure 1: Profiles of head (solid lines), shoulder (long dashes), and pelvis (dashes) and the much smaller head-on-shoulder (dashes) and shoulder-onpelvis (dots) displacements in yaw during a $45^{\circ}(a, b, c)$ and a $90^{\circ}(d, e, f)$ turn for a healthy participant and a PD "off" and "on" medication. Arrows indicate start of foot turn. 


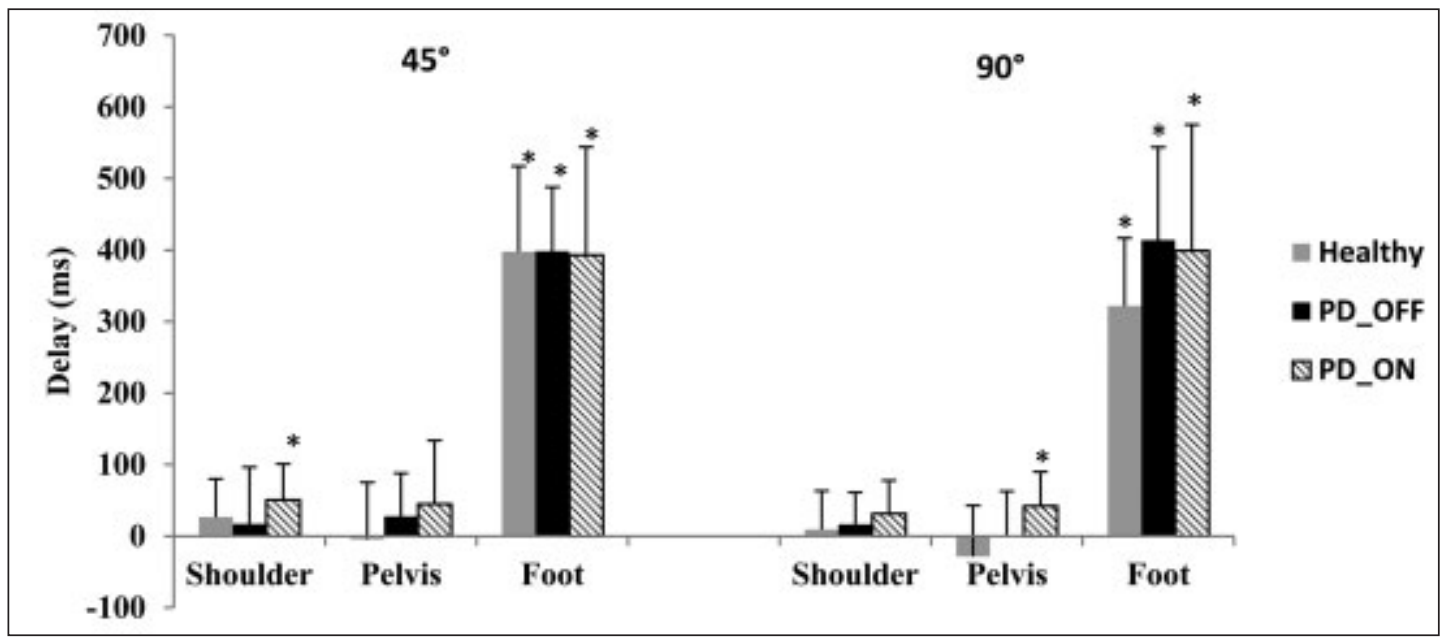

Figure 2: Mean and standard deviation (error bars) of the delays in initiation of reorientation of shoulder, pelvis and foot during $45^{\circ}$ and $90^{\circ}$ turns for healthy controls and people with Parkinson's disease "off" and "on" medication. Stars indicate significant difference from zero. $(\alpha=0.008)$.

$(\mathrm{F}(1,31)=6.16, \mathrm{P}=0.0187)$, and significant segment*magnitude interaction effect $(\mathrm{F}(2,62)=3.74, \mathrm{P}=0.0293)$ on delay times. Examining the significant segment*magnitude interaction effect revealed that while DT-Shoulder and DT-Pelvis were not different during the $45^{\circ}$ and $90^{\circ}$ turns, DT-Foot was significantly longer during the $45^{\circ}$ than $90^{\circ}$ turns (mean \pm std $=424 \pm 150$ and $361 \pm 118 \mathrm{~ms}$ for $45^{\circ}$ and $90^{\circ}$ turns, respectively).

Peak velocity of reorientation was smaller across all segments for PD versus HC participants. ANOVA revealed significant effects of group $(\mathrm{F}(1,31)=10.86, \mathrm{P}=0.0025)$, segment $(\mathrm{F}(2,62)=$ 45.59, $\mathrm{P}<0.0001)$, magnitude $(\mathrm{F}(1,31)=284.20, \mathrm{P}<0.0001)$, segment*group $(\mathrm{F}(2,62)=8.36, \mathrm{P}=0.0006)$, and segment* magnitude $(\mathrm{F}(2,62)=34.49, \mathrm{P}<0.0001)$ on the segment velocities. During both turns and for all segments, the peak velocity was significantly smaller for PD than HC (Figure 3). Furthermore, for both groups and for all segments the peak velocity was significantly greater during the $90^{\circ}$ than $45^{\circ}$ turns (Figure 3). Examining the segment*group interaction revealed that averaged across the two magnitudes of the turn, for each group the velocity of head was significantly greater than the velocity of shoulder and pelvis; however, the difference was larger for $\mathrm{HC}$ than PD participants.

Examining the segment*magnitude interaction effect revealed that averaged across the two groups, there was no difference in the velocity of head, shoulder, and pelvis during the $45^{\circ}$ turns; however, the velocity of head was significantly greater than that of shoulder and pelvis during the $90^{\circ}$ turn (Figure 3).

Magnitude of reorientation was smaller across all segments for PD versus $\mathrm{HC}$ participants. The ANOVA revealed significant effect of group $(\mathrm{F}(1,31)=8.13, \mathrm{P}=0.0077)$, segment $(\mathrm{F}(2,62)=$

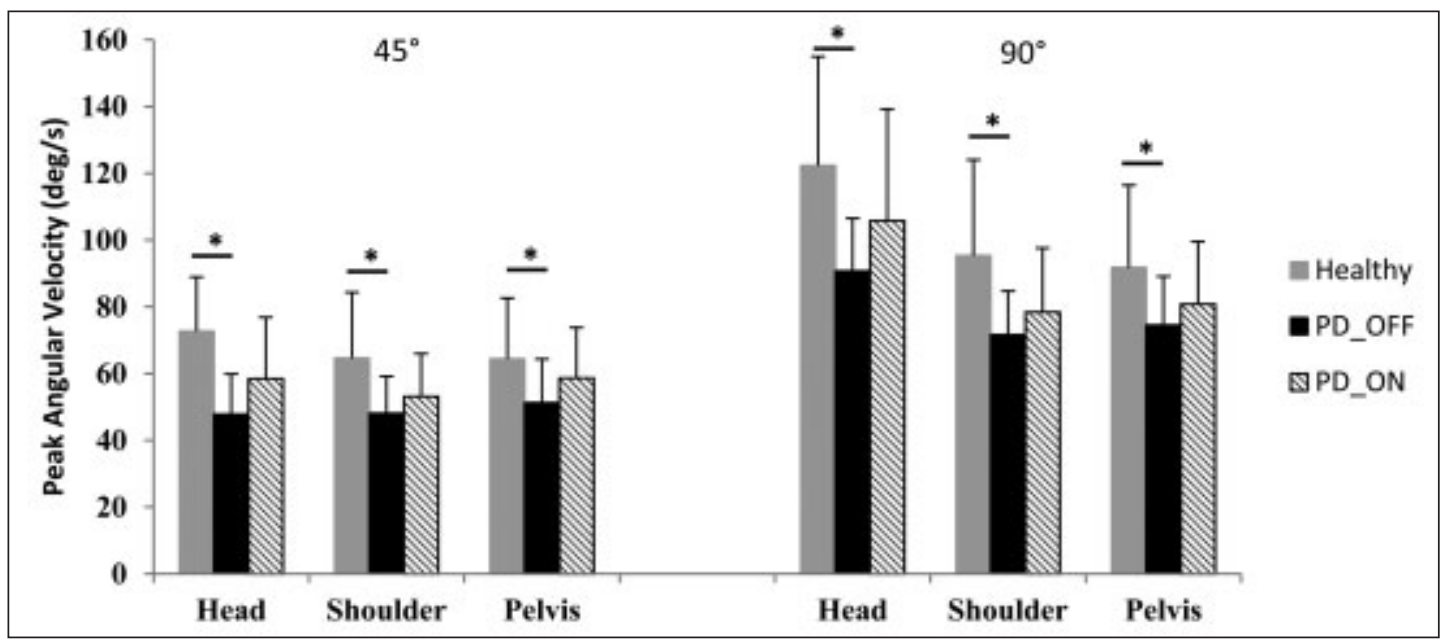

Figure 3: Mean and standard deviation (error bars) of the peak velocity of head, shoulder and pelvis during $45^{\circ}$ and $90^{\circ}$ turns for healthy controls and people with Parkinson's disease "off" and "on" medication. Stars indicate significant differences $(\alpha=0.05)$. 


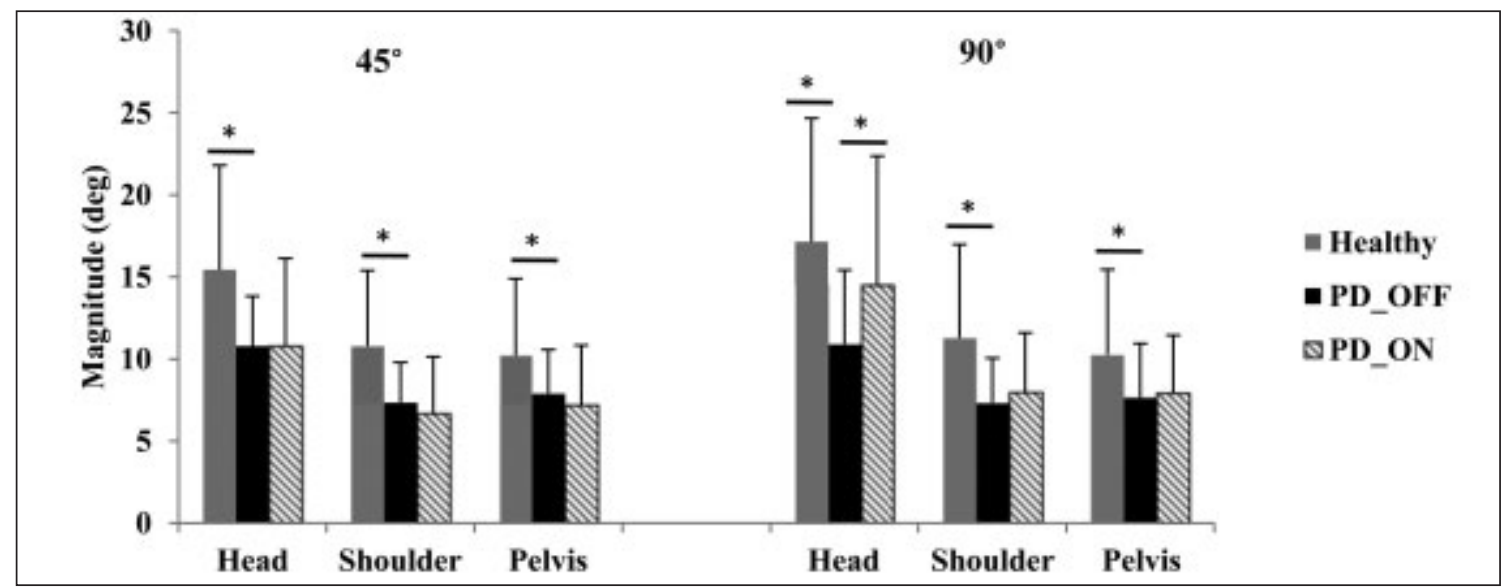

Figure 4: Mean and standard deviation (error bars) of the amplitude of head, shoulder and pelvis turn by the onset of foot displacement during $45^{\circ}$ and $90^{\circ}$ turns for healthy controls and people with Parkinson's disease "off" and "on" medication. Stars indicate significant differences. $(\alpha=0.05)$.

$57.02, \mathrm{P}<0.0001)$, and group*segment $(\mathrm{F}(2,62)=4.76, \mathrm{P}=0.0119)$ on the amount of turn achieved by the onset of ML foot displacement. Tukey's analyses revealed that the amount of turn achieved by each segment was significantly smaller for PD participants than for $\mathrm{HC}$ (mean \pm std $=10.9 \pm 3.8$ and $16.3 \pm 6.9 \mathrm{deg}$ for head, $7.3 \pm 2.5$ and $11.1 \pm 5.1 \mathrm{deg}$ for shoulder, and $7.8 \pm 2.9$ and $10.2 \pm 4.9 \mathrm{deg}$ for pelvis for PD and HC, respectively) (Figure 4). While for both groups the amount of head turn was significantly greater than the amount of shoulder and pelvis turn, the amount of head turn in PD participants was significantly smaller than the amount of head turn in $\mathrm{HC}$ and was similar to the amount of shoulder and pelvis turn of HC (Figure 4).

\subsection{Effects of dopaminergic medications}

The effects of dopamine medication were examined by comparing the performance of PD participants when "off" and "on" medication. Since medication effects are the primary interest of this section, only the main and interaction effects of medication are reported.

The sequence and timing of segment reorientation was similar for PD participants "off" and "on" medication. The ANOVA revealed no significant main or interaction effect of medication on the latencies of shoulder, pelvis and foot reorientation relative to each other. The t-tests revealed that while "off" medication, DT-Shoulder and DT-Pelvis were not different from zero during $45^{\circ}$ and $90^{\circ}$ turns. When "on" medication, DT-Shoulder and DT-Pelvis displayed a small increase; this increase significantly differed from zero for the shoulder during $45^{\circ}$ turns $(\mathrm{t}=3.81, \mathrm{P}=0.0022)$ and for the pelvis during $90^{\circ}$ turns $(\mathrm{t}=3.30, \mathrm{P}=0.0057)$. DT-Foot was significantly different from zero during "off" and "on" medication and for both magnitudes of the turn (Figure 2). Setting aside the small increase in the shoulder and pelvis delay times when "on" medication, these results indicate that regardless of the magnitude of the turn, both HC and PD turned their head, shoulder, and pelvis simultaneously. The simultaneous reorientation of the head and trunk was followed by foot reorientation (Figure 2).

Although medication increased the segments velocity during both small and large turns (Figure 3), this effect was not significant.

ANOVA revealed significant effect of segment $(\mathrm{F}(2,26)=37.51, \mathrm{P}<0.0001)$, segment*medication $(\mathrm{F}(2,26)=3.95$, $\mathrm{P}=0.0318)$, segment*magnitude $(\mathrm{F}(2,26)=4.59, \mathrm{P}=0.0196)$, and segment*medication*magnitude $(\mathrm{F}(2,26)=4.76, \mathrm{P}=0.0173)$ on the amount of turn achieved by the onset of ML foot

Table 2: Functional Axial Rotation (FAR) scores

\begin{tabular}{|c|c|c|c|c|c}
\hline \multicolumn{2}{c|}{ PD Participants (n=14) } & \multicolumn{2}{c}{ Healthy Participants (n=19) } \\
\hline \multicolumn{2}{c|}{ “off" medication } & "on" medication & \multicolumn{2}{c}{ Head } & Shoulder \\
\hline Head & Shoulder & Head & Shoulder & & $43 \pm 10$ \\
\hline
\end{tabular}

FAR scores (degree) of individuals with Parkinson disease "off" and "on" medication and healthy controls. Scores are the average of the scores for the right and left side rotations. 
displacement. Further analyses revealed that only during the $90^{\circ}$ turns and only for the head the magnitude of turn was significantly greater for PD participants while "on" than "off" medication (Figure 4). The mean and standard deviation of head turn at the onset of ML foot displacement was 14.5 $\pm 7.9 \mathrm{deg}$ and $10.9 \pm 4.5 \mathrm{deg}$ for PD participants "on" and "off" medication, respectively (Figure 4).

The Functional Axial Rotation scores revealed no difference between HC and PD patients "off" medication, and between PD patients "off" and "on" medication (Table 2).

\section{Discussion}

This study examined the sequence and timing of reorientation of the head, shoulder, pelvis and feet during on-the-spot turns in healthy elderly and PD participants while "off" and "on" dopaminergic medication. Healthy elderly started turning their head, shoulder and pelvis simultaneously regardless of turn magnitude. Simultaneous reorientation of head and trunk was followed by reorientation of the feet. A similar temporal coordination was observed for PD participants, both when "off" and "on" medication. These findings support and extend the findings of Anastasopoulos and colleagues ${ }^{15,22}$ who showed smaller onset latencies of body segments rotation, especially of the trunk and feet, as healthy individuals and PD participants "on" medication made $45^{\circ}, 90^{\circ}, 135^{\circ}$, and $180^{\circ}$ turns to predictable target locations in "return" trials in comparison with "outbound" trials in which the target locations were not predictable. For both groups the differences in onset latencies of the eyes, head, trunk, and foot rotation were smaller in trials with predictable target locations, resulting in more en bloc rotation of the body. In our study, participants were informed about the direction and the magnitude of the turn before each trial. Therefore, both target location and magnitude of the turn were predictable. Furthermore, participants were instructed to turn at their natural, comfortable speed to face the pre-designated pylon. Considering the predictable nature of the task and the absence of any time constraints, participants in both groups chose the simpler en bloc strategy over the segmented turning strategy. Dopaminergic medications had limited effect on the sequence and timing of segmental reorientation.

Hong and colleagues ${ }^{14}$ reported a craniocaudal sequence of rotation for healthy controls; but no significant differences in the onset latencies of head, trunk and pelvis as PD participants made $180^{\circ}$ on-the-spot turns at their natural, self-selected speed. While the behavior of PD participants is consistent with our findings, that of the HC appears to differ. However, a closer look at the reorientation onset times of $\mathrm{HC}$ reported by Hong and colleagues $^{14}$ does not support a craniocaudal sequence: the differences between onsets of head-trunk or trunk-pelvis turns were statistically insignificant; only the onsets of head-pelvis turn were significantly different.

En bloc turning has the advantage of reducing the dimensionality of the interconnected chain of axial segments to one degree of freedom in order to simplify coordination of movement in the transverse plane. Systematic reduction in the number of degrees of freedom during different tasks as a strategy to cope with the problem of intersegment coordination has been previously reported ${ }^{23-27}$ and is in agreement with the notion proposed by Bernstein ${ }^{28}$ that during repetitive, skilled movements the central nervous system is able to successfully master the redundancy of the number of degrees of freedom. We propose that if the turns were unpredictable (e.g., the direction and/or the magnitude of the turn were indicated by a sudden, unpredictable cue), or if there were time constraints (e.g., participants were instructed to turn as fast as possible) participants might have chosen to turn their body segments in sequence to allow greater degrees of freedom to ensure a successful turn.

The peak velocity of all segments was significantly smaller for PD participants than HC. This result complements reports of lower segments velocity for PD participants in comparison with age-matched controls during standing ${ }^{14-16}$ and walking 9 turns. The lower velocities in PD participants could be due to bradykinesia. Alternatively, slower turns may be a compensatory strategy; PD participants may turn slower to produce less body momentum to be arrested at the end of the turn. Dopaminergic medication caused a small, insignificant increase in segments velocity during both small and large turns.

Examining the amplitude of turn achieved at the onset of ML foot displacement revealed that for each segment the amplitude of turn was significantly smaller for PD participants "off" medication than for HC. This finding is in accordance with the findings of other studies showing reduced amplitude of turn in $\mathrm{PD}^{6,7,14}$. Contrary to the reports of diminished spinal flexibility in PD ${ }^{12,19,29}$, the FAR scores of our PD participants, even while "off" medication, were not different from those of the $\mathrm{HC}$ suggesting that in our study mechanical deficits are not responsible for the reduced magnitude of the turn in PD participants. The smaller amount of turn achieved by PD could be due to their lower angular velocity. Alternatively, smaller turns could be the direct result of PD. Although medication increased the amplitude of rotation of all segments during the $90^{\circ}$ turns, this effect was only significant for head. This finding is in line with reports of limited and insignificant effect of dopaminergic medication on the amplitude of rotation of body segments during on-the-spot turns ${ }^{16}$.

In our study, due to the limited equipment and space, data were recorded only when participants turned to their right. Furthermore, PD participants were not screened for the laterality of their symptoms. Stack and colleagues showed that healthy controls turn similarly to their right and left. Parkinson's disease however, show significant directional differences in step count, turning speed and quality of turn as they make $180^{\circ}$ turns from a standing position to their right and left. Nevertheless, the left/right differences observed in PD participants were not related to the laterality of the symptoms, i.e., turning ability of PD did not differ consistently as they turned towards or away from their most affected side ${ }^{30}$. Hong and colleagues ${ }^{16}$ also report no differences in kinematic measures of turning when PD participants turned toward and away from their most affected side. Nevertheless, considering the directional differences in turning performance of individuals with $\mathrm{PD}^{30}$ and the directional preference of healthy individuals during spontaneous turns $\mathrm{s}^{31,32}$, the effect of direction of the turn on the timing and sequence of reorientation of body segments during on-the-spot turns warrants further investigation. 


\section{Conclusion}

This study was an attempt to further characterize turning performance of individuals with PD participants and has clinical applications in both diagnosis and rehabilitation of turning difficulty in this patient population.

We proposed that turning difficulty in PD might be due to a disturbance in temporal organization of segmental reorientation. Our results do not support such a proposition and show that the temporal organization of segmental reorientation during on-thespot turns remains intact in PD. Parkinson's disease reduces the velocity and early magnitude of reorientation of each body segment which are both slightly improved by dopaminergic medication. However, the most interesting observation of the fact that the $\mathrm{HC}$ and PD patients turn en bloc in the situation when the turn is predictable and with ample time provided, clearly shows that the strategy of en bloc turning is not wrong if the movement parameters are unconstrained. Real life situations often require quick and/or unpredictable turns. It is in these situations that we feel $\mathrm{HC}$ are able to change the strategy from en bloc to sequential segmental turning while PD patients may not and may continue to turn en bloc. In this latter scenario, the en bloc strategy may be unsafe and more likely to result in falls. These differences, which may have implications for rehabilitation strategies, need to be investigated further.

\section{ACKNOWLEDGEMENT}

The authors would like to acknowledge the Natural Sciences and Engineering Research Council (NSERC) and Ontario Neurotrauma Foundation (ONF) for the funding of this research.

\section{REFERENCES}

1. Delong MR. The Basal Ganglia. In: Kandel ER, Schwartz JH, Jessel TM, editors. Principles of neural science. New York: McGraw-Hill; 2000. p. 832-67.

2. Bloem BR, Grimbergen YA, Cramer M, Willemsen M, Zwinderman AH. Prospective assessment of falls in Parkinson's disease. J Neurol. 2001;248:950-8.

3. Giladi N, McMahon D, Przedborski S, et al. Motor blocks in Parkinson's disease. Neurology. 1992;42:333-9.

4. Stack EL, Ashburn AM, Jupp KE. Strategies used by people with Parkinson's disease who report difficulty turning. Parkinsonism Relat Disord. 2006;12:87-92.

5. Glaister BC, Bernatz GC, Klute GK, Orendurff MS. Video task analysis of turning during activities of daily living. Gait Posture. 2007:25:289-94.

6. Carpinella I, Crenna P, Calabrese E, et al. Locomotor function in the early stage of Parkinson's disease. IEEE Trans Neural Syst Rehabil Eng. 2007;15:543-51.

7. Crenna P, Carpinella I, Rabuffetti M, et al. The association between impaired turning and normal straight walking in Parkinson's disease. Gait Posture. 2007;26:172-8.

8. Mak MK, Patla A, Hui-Chan C. Sudden turn during walking is impaired in people with Parkinson's disease. Exp Brain Res. 2008; 190:43-51.

9. Visser JE, Voermans NC, Oude Nijhuis LB, et al. Quantification of trunk rotations during turning and walking in Parkinson's disease. Clin Neurophysio. 2007;118:1602-6.

10. Willems AM, Nieuwboer A, Chavret F, et al. Turning in Parkinson's disease patients and controls: the effect of auditory cues. Mov Disord. 2007;22:1871-8.

11. Morris ME, Huxham F, McGinley J, Dodd K, Iansek R. The biomechanics and motor control of gait in Parkinson disease. Clin Biomech. 2001;16:459-70.
12. Schenkman M, Morey M, Kuchibhatla M. Spinal flexibility and balance control among community-dwelling adults with and without Parkinson's disease. J Gerontol A Biol Sci Med Sci. 2000;55:M441-5.

13. Ferrarin M, Carpinella I, Rabuffetti M, Calabrese E, Mazzoleni P, Nemni R. Locomotor disorders in patients at early stages of Parkinson's disease: a quantitative analysis. Conf Proc IEEE Eng Med Biol Soc. 2006;1:1224-7.

14. Hong M, Perlmutter JS, Earhart GM. A kinematic and electromyographic analysis of turning in people with Parkinson disease. Neurorehabil Neural Repair. 2009;23:166-76.

15. Anastasopoulos D, Ziavra N, Savvidou E, Bain P, Bronstein AM. Altered eye-to-foot coordination in standing parkinsonian patients during large gaze and whole-body reorientations. Mov Disord. 2011;26:2201-11.

16. Hong M, Earhart GM. Effects of medication on turning deficits in individuals with Parkinson's disease. J Neurol Phys Ther. 2010; 34:11-6.

17. Hobson DE, Lang AE, Martin WR, Razmy A, Rivest J, Fleming J. Excessive daytime sleepiness and sudden-onset sleep in Parkinson disease: a survey by the Canadian Movement Disorders Group. JAMA. 2002;287:455-63.

18. Martin JP. The basal ganglia and posture. London: Pitman; 1967.

19. Schenkman ML, Clark K, Xie T, Kuchibhatla M, Shinberg M, Ray L. Spinal movement and performance of a standing reach task in participants with and without Parkinson disease. Phys Ther. 2001;81:1400-11.

20. Horak FB, Frank J, Nutt J. Effects of dopamine on postural control in parkinsonian subjects: scaling, set, and tone. J Neurophysiol. 1996;75:2380-96.

21. Mancini M, Rocchi L, Horak FB, Chiari L. Effects of Parkinson's disease and levodopa on functional limits of stability. Clin Biomech. 2008;23:450-8.

22. Anastasopoulos D, Ziavra N, Hollands M, Bronstein A. Gaze displacement and inter-segmental coordination during large whole body voluntary rotations. Exp Brain Res. 2009;193: 323-36.

23. Mah CD, Hulliger M, Lee RG, O'Callaghan IS. Quantitative analysis of human movement synergies: constructive pattern analysis for gait. J Mot Behav. 1994;26:83-102.

24. Courtine G, Schieppati M. Tuning of a basic coordination pattern constructs straight-ahead and curved walking in humans. J Neurophysiol. 2004;91:1524-35.

25. Gielen CC, van Bolhuis BM. Task-dependent reduction of the number of degrees of freedom in sensorimotor systems. Brain Res Brain Res Rev. 1998;28:136-42.

26. Alexandrov A, Frolov A, Massion J. Axial synergies during human upper trunk bending. Exp Brain Res. 1998;118:210-20.

27. Alexandrov A, Aurenty R, Massion J, Mesure S, Viallet F. Axial synergies in parkinsonian patients during voluntary trunk bending. Gait Posture. 1998;8:124-35.

28. Bernstein NA. The co-ordination and regulation of movements. Oxford: Pergamon Press; 1967.

29. Bridgewater KJ, Sharpe MH. Trunk muscle performance in early Parkinson's disease. Phys Ther. 1998;78:566-76.

30. Stack E, Ashburn A. Dysfunctional turning in Parkinson's disease. Disabil Rehabil. 2008;30:1222-9.

31. Lenoir M, Van Overschelde S, De Rycke M, Musch E. Intrinsic and extrinsic factors of turning preferences in humans. Neurosci Lett. 2006;393:179-83.

32. Taylor MJ, Strike SC, Dabnichki P. Turning bias and lateral dominance in a sample of able-bodied and amputee participants. Laterality. 2007;12:50-63. 